\title{
AASHE Lifetime Achievement Award Winner: Nan Jenks-Jay
}

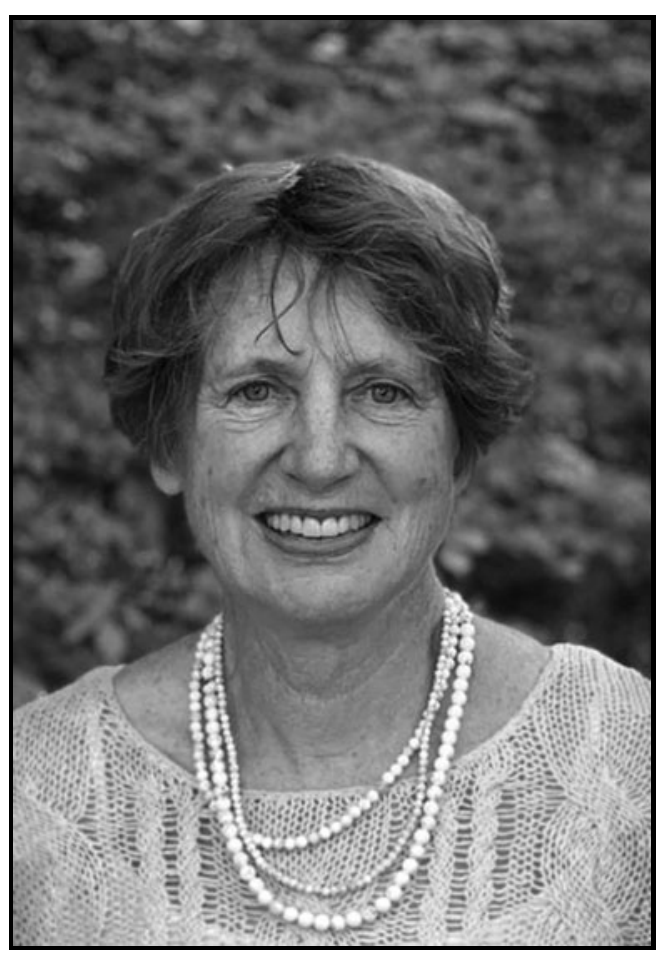

Nan Jenks-Jay was recognized by the Association for the Advancement of Sustainability in Higher Education (AASHE) as a Lifetime Achievement Award Winner in December 2020. Jenks-Jay is known for being a leading voice for the environment and sustainability in higher education. In this interview with Sustainability and Climate Change editor Jamie Devereaux, Nan JenksJay gives us insight into her work, what defines sustainability education, and how the quest for restorative justice can include restoring the climate.

JD: As you helped shape one of the most storied environmental studies and sustainability programs in the US-at Middlebury College in Vermont-could you start with a broad overview on how sustainability and climate change should be incorporated into higher education?

NJJ: Something that all sectors of societygovernment, NGOs, industry, education, etc.-have in common is that they share one planet-a planet we are quickly destroying and with cultures that we have seriously denigrated. Higher education has a unique niche to lead in climate change, equity, and sustainability within its mission to educate young people. More than ever, today's youths dream about making a difference, especially where their elders have failed.

In 2020, higher education globally included about 200 million students. In the US, encompassing two-year institutions to graduate programs, it included about 19 million students. And let's not overlook the growing number of online degree earners not accounted for in these numbers. Within higher education, it's both about making actionable decisions to become models in addressing climate change, equity, and sustainability and about bringing this knowledge, analytical skills, a sense of empathy, and range of competencies to students. For the greater good, and its own benefit, higher education should embed climate change, equity, and sustainability in its mission, policies, programs, and curriculum.

This effort takes on added value when it can be clearly aligned with institutional values 
such as attracting and retaining smart students, engaging talented faculty, enlisting creative staff, attracting interested and expert alumni, and appealing to donors, foundations, and granting agencies. It's important to identify and build alliances with others at the school already touching on this work, but possibly from a different perspective (food studies, global health, social justice, dining service, campus horticulturalist, etc.). Successful integration of climate change, equity, and sustainability throughout an institution is not accomplished in isolation, but as a community.

\section{JD: Has your view on this evolved since you began your career in this area?}

NJJ: Yes, equity and justice need to move from the periphery to the center as a priority.

JD: Middlebury achieved its goal of going carbon neutral back in 2016 (Carbon Neutrality, n.d.). A unique accomplishment! Do you have any advice for leadership (or others, including students, faculty, etc.) who are at institutions looking to do the same?

NJJ: Today with extreme fires and floods, more and more people acknowledge that climate change is the greatest threat to the planet. Climate change and equity have been on a collision course that is further exacerbated by Covid-19. Something has to change and quickly.

Higher education can play a critical role with passionate students, knowledgeable faculty, expert staff, accomplished alumni, and supportive administrators and trustees. Now is a time to recommend a greenhouse gas inventory or to set a goal for carbon neutrality. This effort needs to be strategic in meeting other institutional goals as stated previously, building and reinforcing relationships and attributing credit to others along the way.

Conducting a greenhouse gas inventory to establish a baseline is a first step and an ideal student project. There are countless resources about how to do an inventory. However, my advice about the way to proceed is in partnership with others, for example with a sustainability expert, students, an engineer from campus operations, someone representing equity, a physics professor, and senior administrators. Collaborations are the greatest source of fresh, creative ideas and innovative solutions. Most colleges and universities have already worked on efficiencies or fuel conversations as costsaving measures, so celebrate what is already being done on your campus in a frame of climate change and recognize those involved. Consider alliances with your neighboring community, county, or state energy planners. Link your efforts to the United Nations Sustainable Development Goals (SDGs), for example, goal \#13: Climate Action-"action to combat climate change and its impacts."

Create a goal that is ambitious, has assessed risks and is achievable. Initiatives with distant deadlines are less likely to create momentum and excitement. Having a bold directive from a senior administrator or board of trustees is essential to proceed with confidence and institutional support.

JD: Your position at Middlebury, Dean of Environmental Affairs, is a distinctive deanship among colleges and universities in the US. What is your view on the importance of having someone in that type of high-level role to effect needed systemic changes toward sustainability goals?

NJJ: A senior level appointment such as a deanship truly represents an institution's commitment to education for the environment and sustainability and acknowledges its wide-ranging value. It also sets the bar high with regard to expectations and outcomes. Such a position becomes part of the college's leadership group with a seat at the table to better understand the integral workings of the institution and add a voice in meaningful discussions about its future.

The dean helps to shape guiding documents like strategic plans or master plans while systemically embedding sustainability. Such a position is not to be interpreted as being powerful, but instead as strategic. As dean, 
one provides guidance, insights, leadership, and vision for the greater good of the college and beyond. The position requires navigating a complex system. At Middlebury College, the deanship was created and continued under the enlightened leadership of three presidents. It was designed to encompass the entire enterprise, including the Monterey Institute in California, the summer Bread Loaf programs, study abroad programs, and more, to assist with fundraising and to create bold, attainable goals. Today it is even more imperative that the dean's portfolio not only include DEI (Diversity, Equity, and Inclusion), but that it is made a priority. The greatest outcome of creating a deanship is that sustainability becomes interwoven throughout an institution from curriculum to operations and includes students, faculty, staff, administrators, trustees, and a host of partners.

JD: You were part of an author team who wrote in this Journal that colleges and universities can undergo needed transformations once they "embrace the power of nested networks (Poleman, Jenks-Jay, \& Byrne, 2019)." Could you expound on this idea of nested networks, and do you still see this as a pivotal factor for complex, multilevel institutions?

NJJ: The recent pandemic has amplified the need for and power of nested networks. While Covid-19 has driven some people and programs to be more insular in their thinking, it has also generated innovative alternatives through nested networks that have benefited many. At Middlebury College, one example involves the Knoll organic farm during this past summer.

Dining service staff members whose work was on hold due to the cancellation of summer programs were happily redeployed to help grow 1,700 pounds of donated vegetables for HOPE, the local food shelf serving families in need. The Knoll is nested within the college and the college is nested within the greater surrounding community and county.

On the academic side, students were unable to study abroad this past fall, but some had the opportunity to participate in global work virtually through the Middlebury Global Partnerships in Sustainability Program, the Middlebury Schools Abroad, and the Lake Baikal Eco Center in Irkutsk, Russia. These student interns created a set of challenges designed as a game for teenagers to achieve the UN SDGs. Another team of students working in the Middlebury Sustainable Solutions Lab assisted the Nature Conservancy in Hangzhou, China, to review Best Management Practices for shellfish aquaculture in North America in order to advise aquaculture practices in China to be more sustainable and environmentally friendly.

Students worked through the Sustainable Solutions Lab at Middlebury that was within the broader Global Partnership in Sustainability Programs in Russia and China on goals that are nested within the UN SDGs.

There is a bounty of research regarding the positive impact of societal networks. Additionally, in the study of ecology, networks prove to be more robust against species extinction. The very real idea of becoming extinct or ceasing to exist is a compelling metaphor and rationale for institutions of higher education to engage in nested networks.

JD: The year 2020 was challenging in so many ways to our society and certainly for higher education. Any closing thoughts for those looking to move the needle toward a more sustainable, equitable society through education?

NJJ: The challenges of this past year have brought into sharp focus that which is most important, for example climate change, equity, and justice. During these uncertain times, I've been so impressed by the ingenuity I've observed. People have met the situation squarely and adapted quickly, leaping over traditional barriers to bring about necessary solutions. Individuals have stretched their thinking, reshaped their work, and partnered with others to have real impact. 
There is a theory in evolutionary biology called punctuated equilibrium that is somewhat analogous to what we are seeing today. It is marked by isolated episodes of rapid speciation, or a point in time when new species form quickly rather than evolving over long periods of time with little or no change. Like punctuated equilibrium, I'm currently observing this impressive, rapid change taking place and having beneficial impacts all around us. One positive outcome of this unexpected and unsettled time is the catalytic and extraordinary opportunities to make the change you and your institution want to see and that the world needs.

For those within higher education, it's imperative to look for inspiration everywhere, both within, but especially outside, the academy. Examples abound, such as schools growing vegetables for those experiencing food insecurity and AASHE's virtual and largest conference ever with 7,500 registrants from across the globe, breaking down barriers of cost and distance to be a truly equitable event.

In the upcoming year, people need to maintain their wellness, stay energized, and remain anchored while at the same time being flexible in adjusting to new opportunities. Be the example and solution that higher education is seeking in preparing young people to succeed at whatever they undertake.

In the face of disruption, distractions, deepening climate crisis, and racial disparity and intolerance, now is the time to take a path for restorative justice, and to restore the climate. In the United States, the new political scene will hopefully offer a more supportive atmosphere for this im- portant work to proceed. Embrace this time to leap forward and to lead with sustainability in higher education. Make an impact that makes a difference for your students, institution, community, and the world.

One final, indispensable thought-always remember that with students there is hope.

Nan Jenks-Jay served as dean of Environmental Affairs and taught in the Environmental Studies Program at Middlebury College (Middlebury, VT). In her role as dean, Jenks-Jay worked to advance the college's environmental initiatives and academic programs, as well as foster an integrated institutional vision for sustainability.

For more than three decades Jenks-Jay has been actively involved in the advancement of environmental studies and sustainability programs, their transformation of higher education, and their impact on regional sustainability. She has been immersed in a full spectrum of environmentally-related work as an educator, field scientist, land trust founder, consultant, board member, and administrator. Current areas of specialization include institutional culture and organizational change.

\section{References}

Carbon neutrality. (n.d.). Middlebury College. http://www.middlebury.edu/sustain ability/our-commitment/carbon-neutrality (last accessed December 20, 2020).

Poleman, W. Jenks-Jay, N. \& Byrne, J. Nested networks: Transformational change in higher education. (2019). Sustainability: The Journal of Record, 12(2), 97-99. 